\title{
How to introduce research into university teaching: A training experience in the Universitat Politècnica de València
}

\author{
Amparo Fernández March ${ }^{1}$, Eloina García Félix ${ }^{1}$, Amparo García Carbonell ${ }^{2}$, José V. \\ Benlloch-Dualde ${ }^{3}$, Pilar Bonet Espinosa ${ }^{1}$, Javier Oliver Villarroya ${ }^{4}$ \\ ${ }^{1}$ Institute of Education Sciences, Universitat Politècnica de València (UPV), Spain, ${ }^{2}$ Dept. \\ of Applied Linguistics, UPV, ${ }^{3}$ Computer Engineering Dept., UPV, ${ }^{4}$ Dept. of Computer \\ Systems and Computation, UPV, Spain.
}

\begin{abstract}
In this work we present the project of initiation to the Educational ResearchAction (INED), within the pedagogical training program for university teachers organized by the Institute of Education Sciences (ICE), of the Universitat Politècnica de València (UPV). This project responds to a need for a group of teachers that starts with a professional background and requires training to advance the process of professionalization of teaching, aligned with the concept of scholarship and the movement generated around it.
\end{abstract}

The proposal is formulated as an action research to promote the improvement of teacher training models in higher education. Therefore, it involves a methodology close to the learning communities, so that both the design and implementation involve professors from the university with a background in educational research (6 mentors), pedagogical advisors and experts in different subject areas related to research in higher education.

In this first edition of INED, 25 professors participate and have been selected according to criteria of teaching experience, participation in educational innovation projects and pedagogical training received in different formats.

Keywords: Educational innovation; action research; research methodologies; pedagogical training; teacher training. 


\section{Introduction}

The Institute of Education Sciences (ICE) of the Universitat Politècnica de Vàlencia (UPV) has launched an Initiation Program for Research-Educational Action (INED), aimed at university professors with a certain academic background.

The trajectory of the ICE in supporting the educational development of the UPV is extensive in time and in the variety of actions that have been carried out and are currently carried out. However, the analysis of the effects of some of the actions, both in the change of teachers 'conceptions in relation to the meaning of teaching-learning and in the impact on the students' own learning, place us before a new problem to which we intend to respond. Therefore, we propose an action research project on this issue. The questions on which we pivot this investigation are the following:

How can we redirect some of our actions to align them with a renewed vision of the meaning of "being a good teacher" in the university field? And more specifically:

Can a training action accompany experienced teachers, with a certain background in educational innovation, in the process of addressing a profile of "professor-researcher" on their own teaching?

- What type of program design would be the most appropriate?

- Who should we count on to be able to address it effectively?

- Will the program change the personal conceptions of the participants regarding teaching and learning?

- Will this change have an impact on teachers educational practices? And in the teaching culture of the UPV?

\subsection{Diagnosis of the situation: documentation on the subject}

The progress of the approaches on the training of university teachers depends, to a large extent, on the perspective with which it is faced. There is no doubt that the proposed changes are not solved with the design of training programs that are tried to be implemented expeditiously. As any process of change or innovation belongs to the category of social and political issues, resistant to rationality (Escudero, 1999).

Therefore, facing pedagogical training, from this perspective, means admitting that the most decisive thing is not the type of program or strategy that we must design, but what changes must occur in the structure of values and feelings that weave the identity of the university professor. That the teacher is able to recognize other content and purposes, as well as other types of recognition, that accommodate their professional development and are accepted by the university community. And all this without forgetting that the logic of individual needs, that is, that which arises from practice and is linked to the teaching staff's 
vision, must be combined with the logic of institutional needs. That is, with the challenges that the University, as an institution dedicated to Higher Education, has raised at the present time, and that are translated into true challenges to which the university will necessarily have to respond (Fernández, 2003).

When the differences between a professional and an "amateur" are stablished, it is affirmed that the professional gathers the competences of the creator and the executor, that is, knows how to isolate the problem, poses it, looks for a solution and executes it. All this would be impossible without broad knowledge, academic and specialized knowledge, which never starts from a fresh start. However, despite having resources, the situations that professionals face are always complex, that is, they have something unique, so they always require an adjustment between the prescribed and actual work. If this is true for all professions, in those that deal with the human being, as is the case with education, the prescribable part represents a smaller proportion and a higher qualification is essential. The teacher has to assume high levels of responsibility and an autonomy of action in their decisions and actions would be necessary.

This analysis perspective is what leads us to state that in the design of the university teacher training plans, certain reference frameworks that give congruence and meaning to these plans and that connect with the University's strategic policy in relation to teaching quality are necessary.

Thus, the research project that we present has the purpose of generating a path of professional training for university professors who want to continue developing in the teaching field. In this sense, to base their research project we rely mainly on three aspects:

\subsubsection{The Teaching Academic Development Framework (TADF)}

The Red Estatal de Docencia Universitaria (REDU) committed to the project of developing a framework for teacher qualification for the professional development of university teachers, now approximately two years ago. The first conversations and exchanges were with British experts who had participated in the development and application of the UKPSF (The UK Professional Standards Framework, 2011). After various preparatory conferences and seminars, REDU decided that it was really worth trying to set up a specific framework for Spanish universities and propose it to the university community.

A framework for teacher qualification, whether it is the UK Professional Standards Framework or our proposal for a professional teacher development framework, is always a shared and grounded vision of what it means to be a good teacher and how to move towards there.

A simple vision of the teaching quality, limited to the fulfillment with the classes, the ability to explain well an updated knowledge and the kind answer to the questions of the 
students, requires little of the universities, of the teaching staff or of the educational authorities. From an institutional point of view, if we conceive teaching like this, it is not worth too much effort in teacher training, teacher innovation, teacher evaluation or recognition of teacher quality. It will be enough to ensure sufficient academic quality and to go through some particularly problematic cases of non-compliance or dissatisfaction of students. From the perspective of the teaching staff, a teaching thus conceived is not problematic, beyond finding the necessary time to select and organize the contents of the program and prepare some resources that facilitate its understanding.

From this perspective, it is not well understood to invest too many resources in teacher training or innovation programs, justified simply to the extent that they can provide some technical improvements or practical resources, nothing that makes a big difference. And, from the point of view of the system as a whole, of its policies and evaluations of quality or of the accreditation of its teaching staff, if the educational quality is something so affordable, there is not much to recognize or to promote: why would we have to recognize something as simple when we have much more complex and meritorious challenges such as research.

On the contrary, a vision of advanced and complex teaching, based on the state of the art of research on the factors and practices that make a difference in student learning, sets up a very different picture. It reveals, first, that a great diversity of factors converge in good teaching, many of which require a great deal of knowledge, preparation and experience. It also reveals that achieving a high degree of professionalism and teaching quality is a progressive and long journey, virtually infinite (Paricio, Fernández \& Fernández, 2019).

\subsubsection{The theoretical construct of scholarship (research, training ...) and its crystallization in SoTL}

The relationships between research and teaching are usually complex and unfriendly. The idea that the important thing is to investigate and that teaching is a second level activity for which it is only necessary to master the discipline are widespread. It is usual, therefore, to find teachers who act by intuition, reproducing the guidelines that they have observed in their own teachers and that does not take into account the results of research on teaching and learning in Higher Education when it comes to teaching. Somehow the teaching is developed in a sort of naive amateurism and grows outside the academic world with capital letters.

This predominant pattern is clearly changing in Anglophone countries where "academic being" is acquiring a more diverse and versatile meaning, through networks, societies and scientific journals that are oriented towards the Scholarship of Teaching and Learning (SoTL). 
The SoTL is a renewed conception of what it means to be an academic and has its origin in the report Scholarship Reconsidered: Priorities of the Professoriate (1990) published by Boyer in 1990 at the Carnegie Foundation for the Advancement of Teaching.

Although there is no agreement between researchers to accept a definition of SoTL that is accepted by the scientific community, it can be considered as the most accepted proposal of definition by Shulman (2000): "For an activity to be designated as a scholarship it must manifest at least three characteristics: be public, susceptible to critical review and evaluation, and accessible for exchange and use by other members of the academic community".

Since the early 1990s, this concept has attracted the attention of many researchers in the area of professional teacher development, especially in higher education. SoTL is presented as a model for their professional development and their position towards teaching and learning, which aims to revalue and equate both functions, the teacher and the researcher.

Thus, it can be stated that the SoTL has three objectives: i) to improve the quality of training and student learning; ii) to recognize and value the pedagogical effort; and iii) to propose a professional development framework.

Being a "SCHOLAR" means doing an excellent job and being able to help or guide colleagues towards excellence. In research an academic progresses in his career towards the expert level. SoTL is a frame of reference that affirms that a teacher can (and should) progress until reaching the level of academic in the field of teaching in the same way as he would in the investigation of his disciplinary field. This idea is embodied in actions such as the following:

- Reflect on their teaching, justify the fundamentals of pedagogical resources, get involved in educational innovation, evaluate their teaching to improve it.

- Discuss with colleagues about pedagogical issues, assume responsibilities, incorporate their innovations into their quality process ...

- Publish and make presentations related to their teaching, obtain funds to carry out research on their teaching, help colleagues to train ...

\subsubsection{Design of teacher professional development programs with the greatest potential impact on educational practice}

The involvement of teachers in action research projects is one of the professional development strategies that best fits the purpose of transforming conceptions and beliefs about teaching and learning and overcoming intrinsic barriers in innovation and improvement processes. The structured and systematic inquiry into the practice itself allows to merge training, research and educational action. In this way, the transformation of the practice is no longer a potential effect of the training, but the very object of a research 
process that begins and ends in that same practice and that results in a transformation of both the practice and the educational conceptions of the teachers involved.

The rigor of the method, with its planning, action, observation and reflection phases, allows the construction of practical knowledge that constitutes the very essence of teaching professionalism. That is, the problem of the dissociation between theoretical training (received from the outside) and educational practice (generated from the inside) is solved here with the generation of an own and contextualized knowledge. The diagnosis, the hypothesis-action or the evaluation / final reflection, key moments of the method, demand an intense dialogue between the educational theory and the specific situation. The result is the construction of an own and situated knowledge that is directly linked to the practice and the progressive transformation of that practice.

The improvement of the impact of its activity lies in finding solutions to this double requirement that the teaching professional development of the teaching staff be constructed from reflection and research on their own teaching practice and context and that this effort is framed within a led institutional strategy from the highest levels of command.

Next, we set out the objectives and hypotheses of the action, as well as the planned actions and the observation of the action itself. The training program is detailed, as well as the strategies and evidence for the collection and analysis of data from the research itself.

\section{Objectives}

The objectives proposed by the research are specified in the following:

- To experience an innovative training proposal for university teachers in our educational context.

- To generate a learning community with professors and specialists in university pedagogy through a peer learning methodology that learn and lead the training project.

- To analyze previous conceptions about learning and teaching processes in order to move towards conceptions in which the focus is quality learning.

- To establish a professional development path for university professors in accordance with the Scholarship model.

Of these objectives, we propose two hypotheses: i) teachers participating in the training program that follow the training and advisory guidelines established in the program will acquire skills and knowledge to carry out "adequate" educational research and ii) the training model responds to the training needs of university teachers that can be found at level two and three of the TADF. 


\section{Methodology}

This new training proposal is oriented to the development of research projects with themes aligned with the most relevant factors of the quality of university learning. It has been designed to be carried out in three phases:

- Phase I. Initiation to the research process.

- Phase II. Design or redesign of the research project and research protocol publication.

- Phase III. Development and dissemination of research.

In order to ensure and optimize the quality of the program, requirements for access to the program and basic commitments have been established both by the participants and the mentors: i) to be participating or having participated in an Educational Innovation and Improvement Project (PIME) or / and Educational Innovation and Quality Team (EICE) during the last three years (4 points out of 10); ii) to prove a teaching experience of at least 5 years (1 point out of 10$)$; iii) to prove participation in ICE training programs (1.5 points out of 10); iv) formal commitment to the conditions of the program (apprenticeship contract) (1.5 points out of 10); and v) interview (2 points out of 10).

Taking these requirements into account, a total of 28 participants have been selected, who have a series of commitments to the program:

- Attend and actively participate in the training activities that arise.

- Design an educational research or action research. If you have an educational innovation in process, you can redirect it towards research.

- Participate in follow-up meetings convened by UPV mentors.

- Follow the mentors' guidance and recommendations throughout the entire process (design, development, evaluation and dissemination).

- Prepare a scientific article on the research carried out with the objective that it can be published in high-impact journals.

On the other hand, being a long-term training, in action, which aims to support the transit process towards a vision of the more developed teaching profession, there are also some commitments from the mentors. Therefore, there are two types of mentoring:

1. Advice by the trainers in the thematic areas that will be addressed in the training.

2. Personal advice: each participant will be assigned an ICE tutor and a UPV teacher linked to educational research in the same area of knowledge. The advice will be at the individual and group level, since subgroups of work will be created, formed by four or five teachers, related to educational research issues and concerns.

Both tutors (UPV faculty and ICE advisors) will accompany the participants throughout the training process. Finally, those who have regularly followed the entire training process and 
have prepared the research article with sufficient quality level to be published in highimpact journals, will obtain recognition of 5 ECTS from ICE.

The detailed program of this training action is presented below in Tables 1 and 2:

Table 1. Planning of training activities of the INED program (I and II phases)

\begin{tabular}{|c|c|c|c|}
\hline \multicolumn{4}{|c|}{ I: Initiation to the investigation process (January to March 2018) } \\
\hline \multirow{3}{*}{$\begin{array}{l}\text { Training } \\
\text { Modules }\end{array}$} & Thematic areas & Modality & Strategy \\
\hline & $\begin{array}{l}\text { Where, how and when to } \\
\text { publish about educational } \\
\text { research? }\end{array}$ & $\begin{array}{l}\text { Round table } \\
\text { (3 hours) }\end{array}$ & Valuation day report \\
\hline & $\begin{array}{l}\text { The focus of research on } \\
\text { higher education }\end{array}$ & $\begin{array}{l}\text { Workshop } \\
\text { (4 hours) }\end{array}$ & $\begin{array}{l}\text { My research focus. Intra- } \\
\text { group debate }\end{array}$ \\
\hline \multicolumn{4}{|c|}{ II: Research design and research protocol publication (March to Juny 2018) } \\
\hline \multirow{3}{*}{$\begin{array}{l}\text { Training } \\
\text { Modules }\end{array}$} & $\begin{array}{l}\text { Design of educational } \\
\text { research projects in the } \\
\text { classroom }\end{array}$ & $\begin{array}{l}\text { Workshop } \\
\text { (9 hours) }\end{array}$ & $\begin{array}{l}\text { Guided work. } \\
\text { Autonomous work: DAFO }\end{array}$ \\
\hline & $\begin{array}{c}\text { Data analysis } \\
\text { methodologies: } \\
\text { quantitative }\end{array}$ & $\begin{array}{l}\text { Workshop } \\
\text { (8 hours) }\end{array}$ & Rating Sheet \\
\hline & $\begin{array}{l}\text { Data analysis } \\
\text { methodologies: qualitative }\end{array}$ & $\begin{array}{l}\text { Workshop } \\
\text { (8 hours) }\end{array}$ & $\begin{array}{l}\text { Description of the data } \\
\text { collection and analysis } \\
\text { process in the draft project }\end{array}$ \\
\hline \multirow[b]{2}{*}{$\begin{array}{l}\text { Educational } \\
\text { Research } \\
\text { Project }\end{array}$} & Objectives & Modality & Follow up \\
\hline & $\begin{array}{l}\text { Design / redesign the } \\
\text { educational research } \\
\text { project. } \\
\text { Develop a protocol } \\
\text { according to the format } \\
\text { that will be provided for } \\
\text { publication. }\end{array}$ & $\begin{array}{l}\text { Personal and / or } \\
\text { small group work, } \\
\text { with mentor } \\
\text { supervision }\end{array}$ & $\begin{array}{l}\text { Personal tutoring: } \\
\text { mentoring supervision. } \\
\text { Joint session: share } \\
\text { design protocols } \\
\text { Monitoring "We learn } \\
\text { among equals": project } \\
\text { development and } \\
\text { resolution of doubts } \\
\text { Virtual forums }\end{array}$ \\
\hline
\end{tabular}


Table 2. Planning of training activities of the INED program (III phase)

\begin{tabular}{|c|c|c|c|c|}
\hline \multicolumn{5}{|c|}{ III: Research development and dissemination (September 2018 to May 2019) } \\
\hline \multirow{3}{*}{ Training Module } & \multicolumn{2}{|c|}{ Thematic areas } & Modality & Strategies \\
\hline & \multicolumn{2}{|c|}{$\begin{array}{l}\text { Dissemination of the results of educational } \\
\text { research }\end{array}$} & $\begin{array}{l}\text { Workshop } \\
\text { (4 hours) }\end{array}$ & $\begin{array}{l}\text { Autonomous } \\
\text { work } \\
\text { Tutorials }\end{array}$ \\
\hline & \multicolumn{2}{|c|}{ "Challenges of educational research" } & $\begin{array}{l}\text { Lecture } \\
\text { (4 hours) }\end{array}$ & $\begin{array}{c}\text { Debate } \\
\text { Personal } \\
\text { assessment }\end{array}$ \\
\hline \multirow{2}{*}{$\begin{array}{c}\text { Educational } \\
\text { Research Project }\end{array}$} & Objective & Modality & \multicolumn{2}{|c|}{ Follow up } \\
\hline & $\begin{array}{l}\text { Prepare the article } \\
\text { for later publication }\end{array}$ & $\begin{array}{l}\text { Personal and / or } \\
\text { small group work }\end{array}$ & \multicolumn{2}{|c|}{$\begin{array}{l}\text { Personal tutoring: } \\
\text { supervision of mentors } \\
\text { Follow-up session }\end{array}$} \\
\hline
\end{tabular}

\section{Results and conclusions}

The program is currently in the final phase of execution. The participating professors have already carried out their field work and have collected the data and evidence that allow them to rigorously analyze what happened and to draw conclusions. After this process will come the writing of their work in scientific article format. This is the ultimate goal of the program and we assume that not all participants will have a final product of sufficient quality to be sent to periodical publications of a certain level. However, the most important thing is to have been able to involve them in a systematic and rigorous process of action research on the learning and teaching of their subjects and achieve a change of conceptions about teaching. Participants in the program move towards more complex conceptions and more aligned with what research in higher education suggests.

Below, we summarize some of the most relevant results so far.

The focus of interest in relation to participants research was focused on the following topics:

- Evaluation to learn: means of assessment, instruments (rubrics)

- Methodologies that favor active, deep learning, which pose an intellectual challenge

- Impact of ICT in learning skills

- Curriculum design of the soft skill "learn to learn" throughout the training

- Study of the quality of learning environments:

○ Participatory tools 
- Resources for learning

- Social networks

○ Virtual environments

- Studies on motivation to learn (deep learning vs. superficial learning)

- Peer interaction and cooperation

Clarifying what the participating professors wanted to investigate and how they were going to do it has been one of the critical process points. They have had difficulties, on the one hand, in specifying the research question and, on the other, in the review of the related literature and in the understanding of the research object we face when we talk about education.

Here are some examples of the research questions / objectives:

- Perception of the utility (task value) of a subject improves involvement.

- How can we assess teamwork competence through the realization of a Project Management Plan?

- Peer instruction and involvement.

- Do motivated students get better results?

- Is the combination of screencast and its evaluation an effective methodology to train ethical reflection?

- Can the use of Cloud Computing technologies facilitate students' self-regulation to improve the degree of achievement of learning objectives in Digital Systems Design?

- Determine the extent to which the activities described contribute to raise awareness / awareness of the challenges posed by the 2030 Agenda and to generate students more involved and committed to the learning objectives and specific results of the subjects.

- Does the methodology of critical analysis of texts performed individually and contrasted in small groups improve the ability of critical thinking of students? Does it also improve students' self-perception about their ability in this competition?

- The ApS is a methodology that allows the integration of second language learning into ICT training environments: case study.

The analysis of the research protocols allows us to draw some conclusions about how the participants have evolved. The first conclusion is that, in some cases, theoretical frameworks reflect a good conceptualization of the problem they want to study and have found good support in the scientific literature, which will allow their results to be compared with the theory that supports them. and with similar research. Second, they have been able to present various validated instruments, which will undoubtedly result in a greater consistency of their research. Third, in the methodological proposals there are some problems to isolate variables, some lack of knowledge of the most appropriate techniques for their analysis and fear of also incorporating a more qualitative perspective in their work. 
A third piece of information we present refers to the result of a working session with the participants in which they were asked to reflect on the opportunities and barriers that the program was posing for them. This activity was done first individually and then in a group.

Next, we present the most relevant.

Stronger barriers: Lack of time, lack of recognition (Departments, colleagues, among other).

Less strong barriers: Lack of guidance, measuring instruments, data analysis.

Facilitators: Personal satisfaction, INED (training, accompaniment, sharing, among other), personal motivation (usefulness, learning, improvement of teaching), participating in Innovation Projects or Teams.

\section{References}

Boyer, E. L. (1990). Scholarship reconsidered: Priorities of the Professoriate. Special Report, Carnegie Foundation for the Advancement of Teaching. New York: JosseyBass.

Escudero, J. M. (1999). La formación permanente del profesorado universitario: cultura, política y procesos. Revista Interuniversitaria de Formación del Profesorado, 34, 133157.

Fernández, A. (2003) Formación pedagógica y desarrollo profesional de los profesores de universidad: análisis de las diferentes estrategias. Revista de Educación, 331, 171-211.

Paricio, J., Fernández, A., \& Fernández, I. (Eds.) (2019). Cartografía de la buena docencia universitaria. Un marco para el desarrollo del profesorado basado en la investigación. Narcea.

Shulman, L. (2000). From Minsk To Pinsk: Why A Scholarship of Teaching and Learning? Journal of the Scholarship of Teaching and Learning, 1(1), 48-53. Retrieved July 2, 2019 from https://scholarworks.iu.edu/journals/index.php/josotl/article/view/1582

The UK Professional Standards Framework. For teaching and supporting learning in higher

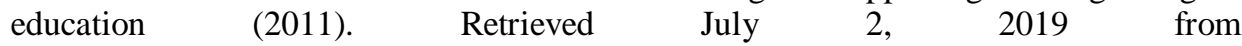
https://www.heacademy.ac.uk/system/files/downloads/uk_professional_standards_fram ework.pdf 